\title{
Lévi-Strauss, teórico da comunicação
}

\section{RESUMO}

O presente trabalho pretende apresentar uma visão sumária das concepções de Claude Lévi-Strauss sobre comunicação. Pretende também relatar algo da importância dos insights comunicacionais na edificação da monumental obra deste autor. Percorre então sinteticamente sua explicação do parentesco e da proibição do incesto, sua concepção comunicacional a respeito das relações entre culturas, sua teoria sobre o pensamento selvagem e a lógica do concreto. Finalmente, examina o tratamento semiótico que dedicou à mitologia.

\section{PALAVRAS-CHAVE}

modelo linguístico

teoria da comunicação

sociabilidade

\section{ABSTRACT}

This paper aims to present a synthetic approach to the lévistraussian perspective concerning social communication. It intends also to show that his insights on communication performed a very important role in the construction of his monumental oeuvre. Specifically, this article briefly considers the relevance of Lévi-Strauss' ideas about social communication as a basic tool for his theory of kinship, incest prohibition and for his understanding of the relationship between cultures. Besides, this work examines the place of communication in his concepts of savage mind and of logic of the concrete. Finally, we examine the semiotic treatment Lévi-Strauss dedicated to mythology.

\section{KEY WORDS}

linguistic model

theory of communication

mythology
Claude Lévi-Strauss é um dos pensadores mais influentes de nosso tempo. Nascido em Bruxelas em 1908, o antropólogo francês apareceu desde cedo como uma das figuras mais importantes do vigoroso movimento intelectual que veio a ser conhecido como Estruturalismo uma perspectiva sobre a ciência que afetou enormemente o conjunto das disciplinas do campo das ciências humanas, sobretudo nas décadas de 1960 e 1970. Em certo instante este movimento foi visto como reunindo personagens e pensamentos tão diversos como os de Roland Barthes (1915-80), Jacques Lacan (1901-81), Michel Foucault (1926-84), Pierre Bourdieu (1930-2002) e Louis Althusser (1918-90). Retrospectivamente, pode-se afirmar que o estruturalismo teve como fator de convergência a importância que atribuiu ao fenômeno da significação e, em alguns casos, da comunicação.

Durante a Segunda Grande Guerra, como tantos intelectuais de origem judaica, Lévi-Strauss protegeu-se da ameaça nazista nos Estados Unidos. Em Nova Iorque, conheceu o grande linguista russo Roman Jakobson (1896-1982), figura relevante da Escola Linguística de Praga, que lhe apresentou os princípios e métodos da Linguística Estrutural, propostos por Ferdinand de Saussure (1857-1913). Saussure tinha aberto caminhos inteiramente novos para o estudo científico da língua, ao defender a ideia de que a identidade de cada elemento linguístico se define negativamente com relação àquilo que este elemento não é. Por exemplo, os fonemas que compõem a palavra "árvore" só desempenham função de significação na medida em que difiram dos fonemas de outras palavras. Como consequência desse princípio, cada elemento do sistema linguístico passa a ter sua significação definida por sua relação com todos os demais. E a significação de cada elemento passa a conter virtualmente a totalidade do sistema a que pertence. Esta concepção de sistema foi a que Lévi-Strauss tomou como modelo no desenvolvimento de sua Antropologia Estrutural.

\section{0 parentesco e 0 incesto}

Causou imenso impacto nos meios científicos a publicação em 1949 do monumental As Estruturas Elementares do Parentesco. Neste livro, Lévi-Strauss adicionou os princípios de Saussure à teoria da reciprocidade proposta por Marcel Mauss (1872-1950) em seu importantíssimo Ensaio sobre a dádiva (1923). Partindo de estudos sobre rituais de trocas de presentes em algumas sociedades do Pacífico ocidental e do noroeste do continente americano, Mauss percebeu que a obrigação de reciprocidade fazia dos atos de dar, de receber e de retribuir uma unidade única, não três operações separadas.

Com base nessa ideia, Lévi-Strauss propôs que as alianças matrimoniais poderiam ser consideradas como

\author{
José Carlos Rodrigues \\ Professor do Programa de Pós-Graduação em Comunicação Social da \\ PUC-Rio/RJ/BR \\ jcsrodri@terra.com.br
}


sistemas de comunicação comparáveis às trocas de presentes. Assim, a obrigação de reciprocidade faria de cada grupo social "doador" um "credor" virtual de presente matrimonial. Uma das novidades mais importantes que Lévi-Strauss introduziu foi demonstrar que as unidades dos sistemas de parentesco não são as famílias isoladamente, mas as relações entre estas - mais ou menos como acontece nos sistemas linguísticos. Além disso, Lévi-Strauss ousou comparar pessoas a elementos de uma linguagem: aquelas, como estes, circulam na sociedade, entre os grupos sociais e adquirem valores diferenciados conforme as relações que entretenham com os demais elementos integrantes de um sistema de permutas matrimoniais.

\section{Para ele, em toda sociedade poder-se-iam distinguir} esquematicamente pelo menos três estruturas de comunicação inter-relacionadas: comunicação de mensagens propriamente linguísticas, comunicação de bens e serviços e, como acabamos de ver, comunicação de parceiros matrimoniais.

Um dos resultados desse esforço intelectual foi o extraordinário feito de reduzir a colossal variedade de sistemas de parentesco a um número relativamente pequeno de estruturas de comunicação. Essas estruturas são "elementares" quando tanto as trocas proibidas quanto as permitidas entre os grupos familiares encontramse predefinidas pelas regras de alianças matrimoniais. São "complexas", em sua terminologia, aquelas em que apenas as conjunções interditadas se veem predeterminadas. Na grande maioria dos casos estas duas estruturas de comunicação envolvem apenas duas formas básicas de troca: "restrita", na qual um grupo A recebe do mesmo grupo B a que costuma conceder um cônjuge; "generalizada", quando um grupo A cede a um B que oferece a $\mathrm{C}$ que doa a $\mathrm{N}$ que retribui a $\mathrm{A}$.

Foi também nesta perspectiva comunicacional que o grande antropólogo apresentou sua revolucionária teoria sobre as razões da universalidade da proibição do incesto nas sociedades humanas. Seu primeiro passo foi desmontar as explicações até então existentes. Estas teo- rias vinculavam a universalidade da proibição quer a um alegado horror instintivo ao incesto, quer a uma ausência de atração física entre parentes excessivamente próximos, quer ainda a uma atitude defensiva destinada a evitar riscos de degeneração biológica contidos nos cruzamentos consanguíneos. Os argumentos de LéviStrauss para esta desmontagem parecem simples hoje. Mas não era o que acontecia em 1949.

Contra a explicação biológica, para a qual as sociedades perceberiam espontaneamente os riscos de degenerescência, Lévi-Strauss respondeu que esta teoria contradiz as observações científicas. Segundo tais observações, o cruzamento endogâmico é exatamente aquilo que garante a permanência de uma linhagem nas espécies animais e vegetais. Portanto, a teoria que apela aos riscos genéticos padece de inversão entre causa e consequência. Além disso, argumentou Lévi-Strauss, na medida em que a proibição do incesto constitui uma prática universal, resulta pouco verossímil que a totalidade das culturas participe universalmente de um idêntico saber sobre os invocados perigos biológicos das relações consanguíneas. Semelhante improbabilidade faz-se ainda mais veemente quando verificamos que os registros etnográficos testemunham que não raramente podemos encontrar sociedades proibindo relações entre parentes geneticamente muito distantes, ao passo que as admitem entre parceiros biologicamente próximos.

Quanto às explicações de tipo psicológico, primeiro é necessária uma ponderação sobre os significados de "excessivamente" próximo ou distante, para habitantes de pequenas aldeias holísticas ou de grandes metrópoles individualistas. Em segundo lugar, Lévi-Strauss lembra que as pesquisas etnográficas frequentemente mostram um panorama de atração sexual entre parentes próximos bastante distinto daquele sugerido pela ideia de "repulsa" que a teoria carrega. Além disso, talvez não seja irrelevante o fato - bastante curioso, aliás - de ter sido exatamente sobre a tecla oposta (atração entre parentes próximos) que a psicanálise insistiu. Finalmente, Lévi-Strauss contra-argumentou: mas por que razão proibir por toda parte aquilo que em lugar algum se quer praticar?

Em substituição a estas teorias, como segundo passo, Lévi-Strauss sustentou uma explicação de natureza comunicacional. Segundo ele quando se proíbe a um homem ou mulher que mantenha relações sexuais com indivíduos de seu próprio grupo acaba-se tornando imperativo que as realize com indivíduos de outro. Dessa forma, ao colocarem os grupos familiares em articulação recíproca, as relações sexuais e a reprodução populacional transformam-se em dispositivos sociológicos. Logicamente a comunicação entre clãs, famílias, etc. cessará e a sociedade correrá risco de pulverização no caso de os indivíduos passarem a sistematicamente se casar dentro de seus próprios grupos de origem. Em síntese, o incesto resume-se a uma espécie de recusa de comunicação. Da mesma forma, a negativa à comunicação pelo 
menos em princípio passa a se dotar de um caráter incestuoso. Este tipo de proibição não se limita então apenas às relações sexuais, mas repercute sobre o conjunto do universo simbólico.

\section{As relações entre culturas}

No início dos anos 50 Lévi-Strauss voltou a tematizar a comunicação. Na terceira parte de um artigo eminentemente teórico dedicado à noção de estrutura social (LéviStrauss, 1953) propôs considerar as relações entre os grupos sociais e a própria sociedade em seu conjunto sob a perspectiva de uma teoria da comunicação. Para ele, em toda sociedade poder-se-iam distinguir esquematicamente pelo menos três estruturas de comunicação inter-relacionadas: comunicação de mensagens propriamente linguísticas, comunicação de bens e serviços e, como acabamos de ver, comunicação de parceiros matrimoniais. Neste texto a ideia de comunicação aparece para Lévi-Strauss como possibilidade de desenvolver uma apreensão globalizante dos sistemas sociais.

A partir desta perspectiva o estudo dos sistemas sociais pode ser entendido como busca por uma lógica comunicacional. Esta lógica, para Lévi-Strauss, é algo muito diferente daquilo que poderíamos resumir na ideia de "comunhão". Comunhão pressupõe ascendência e hegemonia da semelhança, enquanto comunicação constitui um jogo complexo de semelhanças e de diferenças, de aproximações e de afastamentos, de convergências e de divergências. Comunhão significa triunfo do Mesmo, mas a comunicação só é possível como dialética de Alteridades, isto é, como algo que acontece em algum ponto entre um máximo de distância e um máximo de proximidade. Em uma cápsula, semelhança demasiada, comunicação impossível; diferença em excesso, idem.

Comunicação, portanto, pressupõe semelhança e diferença. Por isso ela nunca chega à comunhão, este estado de convergência total em que comunicar não tem mais razão de ser, uma vez que idênticos nada têm a trocar. Em outras palavras, o mesmo não pode se comunicar com o mesmo. E isto parece bastante óbvio: afinal, que informação transmitir no estado de comunhão? Comunhão, portanto, é um estado ou utopia que dispensa a comunicação. É preciso pois marcar atenta distância entre comunicação, como instrumento teórico - que inclui o conflito - e comunhão, como ideologia nada raramente política ou religiosa.

Esta concepção de comunicação está na raiz do conhecidíssimo ensaio Raça e história, publicado no mesmo ano de 1952 em que foi proferida a conferência que resultou no artigo sobre a noção de estrutura. Raça $e$ história foi uma resposta a uma solicitação da Unesco no sentido de que Lévi-Strauss se manifestasse a respeito da questão racial diante da ciência moderna. Neste trabalho, Lévi-Strauss abordou o problema da diversidade das culturas, levando em conta suas relações internas bem como suas relações recíprocas. Definiu-as em função de um optimum de diversidade além do qual as sociedades não poderiam ir, mas aquém do qual não poderiam descer sem perigo. Tal optimum variaria em função do número de sociedades, do quantitativo de cada uma, do afastamento físico entre elas e dos meios de comunicação de que lançassem mão.

Lévi-Strauss não contestou que a diversidade das culturas tivesse a ver com os afastamentos geográficos, com a fisionomia específica do ambiente ecológico de cada sociedade e com o desconhecimento que cada cultura pudesse ter das demais. Mas argumentou: esses fatos só seriam rigorosamente verdadeiros como explicações da diversidade cultural se cada sociedade tivesse se desenvolvido isoladamente de outras - algo que só muito rara e apenas muito transitoriamente ocorreu. As sociedades humanas nunca estão sós: por consequência, ao lado das diferenças atribuíveis à distância, é sempre necessário considerar aquelas diferenças que se devem à proximidade, aquelas que resultam do esforço de cada sociedade em diferir, em se opor às demais, em ser ela mesma. Os sistemas simbólicos - que são as culturas - encontram, portanto, um lugar no âmbito da dialética de aproximação e de afastamento a que acima nos referimos.

Encontramos em ação o mesmo princípio quando LéviStrauss reflete sobre a questão da formação dos megasistemas culturais, estas espécies de superorganismos coletivos, que são as chamadas "civilizações" - culturas amplamente difundidas, às vezes mesmo globalizadas ou mundializadas. As megaculturas jamais são obras de sociedades isoladas. Não resultam do modo particular de ser de cada uma; derivam antes de um número importante de entidades sociais que se conjugam por meios variados - migrações, comércio, guerras, empréstimos, comunicação, enfim. As civilizações dependem da conjunção e da coalizão de diferenças que se fecundam reciprocamente e resultam em novas diferenças. É desta multiplicidade que se nutrem. Entendida como comunhão, a ideia de uma civilização mundial, para Lévi-Strauss, não passa de um conceito limite.

\section{[....] a ideia de comunicação aparece para Lévi-Strauss como possibilidade de desenvolver uma apreensão globalizante dos sistemas sociais.}

O grande antropólogo não se distrai sobre os perigos éticos e políticos envolvidos nos movimentos unilaterais de expansão que tendem a estabelecer uma monocultura de alcance mundial. Pelo contrário, são muitas as passagens de suas obras em que estes riscos são tematizados. Mas na raiz de seu pensamento semelhan- 
te preocupação não é apenas ética ou política. É eminentemente teórica. Do ponto de vista da teoria da comunicação de que Lévi-Strauss faz uso, não há - nem pode haver - uma civilização mundial em sentido absoluto, uma civilização em que as diferenças estariam abolidas: tal sociedade é impossível teoricamente e a iminência dela seria também a iminência do fim. Para ele a humanidade se vê constantemente às voltas com dois processos, dos quais um tende a instaurar a semelhança e a unificação, enquanto o outro procura manter ou restabelecer a diversificação. Trata-se de duas maneiras simultâneas e indispensáveis de a humanidade se fazer. A hegemonia de uma das direções significaria o oposto disso, entropia - caso em que, em suas palavras, a antropologia passaria a ser uma "entropologia".

\section{0 tratamento semiótico da mitologia}

Na década de 1960, Lévi-Strauss voltou a impactar o pensamento das ciências humanas com a publicação de O Totemismo Hoje (1962), O Pensamento Selvagem (1962) e de sua gigantesca tetralogia, Mitológicas, começada em 1964 e cujo último volume veio à luz em 1971. O desafio a que estas obras fizeram frente é simplesmente portentoso. $\mathrm{O}$ primeiro passo foi desconstruir o conceito de totemismo e mostrar como a ilusão etnocêntrica que contém impede a constatação de uma forma de pensamento universal nas sociedades humanas. Conforme LéviStrauss ensinou, por esta forma universal de pensamento sistemas de diferenças percebidas entre elementos da natureza (animais, plantas, acidentes geográficos, etc.) são aproveitados por todas as culturas para classificar e significar sistemas de diferenças entre os elementos da sociedade (clãs, famílias, torcidas de futebol, por exemplo).

A partir daí, em O Pensamento Selvagem, Lévi-Strauss aplicou-se a demonstrar a inexistência de qualquer desigualdade entre o modo de operação cognitiva dos povos ditos primitivos e o das sociedades consideradas civilizadas. O fato de reconhecermos nestas últimas um pensamento "cultivado" ou "domesticado" (ciência, filosofia, etc.) não implica que nelas tenha deixado de ser operante o pensamento em estado "selvagem", baseado em comunicação direta entre o mundo, os órgãos da sensibilidade e o intelecto. Da mesma maneira, um pensamento reflexivo, disciplinado, sofisticado e sistemático não está ausente das sociedades que nossa cultura considera "selvagens". Esses modos de pensamento não se excluem. Pelo contrário, Lévi-Strauss observou que devemos à combinação deles a conquista universal das "artes fundamentais da civilização": controle do fogo, cerâmica, tecelagem, domesticação dos animais, agricultura, entre outras. Sem tais realizações técnicas e cognitivas, efetuadas por povos que consideraríamos primitivos, as civilizações de que nos orgulhamos teriam sido literalmente impossíveis.

O ponto central dessa argumentação para nossos propósitos reside no fato de Lévi-Strauss propor com o con- ceito de pensamento selvagem que uma via de mão dupla existe na comunicação entre a cultura e a natureza: entre o homem e o mundo tecem-se redes de mensagens e de significados, conexões entre propriedades da subjetividade e do cosmos. O pensamento selvagem consiste em uma lógica do concreto, segundo sua expressão, que opera diretamente no nível dos signos e dos órgãos dos sentidos. Esta lógica consiste de postulados e de axiomas que não dissociam o sensível e o inteligível, que consideram as formas como signos e as ideias como formas perceptíveis. A lógica do concreto pressupõe que tais sistemas de significação possam se expressar uns por meio de outros, colocando as categorias sensíveis em relações de isomorfismo ou de oposição, descobrindo entre si relações de equivalência, sem que lhes seja obrigatório o recurso a um nível de mediação formal, abstrato ou conceitual.

\section{Comunicação, portanto, pressupõe semelhança $e$ diferença. Por isso ela nunca chega à comunhão, este estado de convergência total em que comunicar não tem mais razão de ser, uma vez que idênticos nada têm a trocar.}

O mundo abandonou o silêncio semiótico. No pensamento selvagem as propriedades lógicas e significacionais se manifestam de maneira direta, como atributos das coisas, simultaneamente aos órgãos de sentidos e ao intelecto: animais, plantas, fenômenos meteorológicos, acidentes geográficos aparecem nos mitos e nos rituais porque antes foram minuciosamente observados e classificados. Seus detalhes e características (cores, odores, ruídos, tatos, formas, hábitos, dimensões...) foram tomados como ferramentas intelectuais, isto é, foram absorvidos como significantes atuais ou virtuais em um sistema de posições e de oposições, de redundância, de permutações, simetrias, contrastes, semelhanças, analogias, homologias, inversões, identificações, isomorfismos, metáforas, metonímias. Suas propriedades são codificadas e recodificadas como integrantes de um sistema de transformações, enfim. Assim, os elementos da natureza escolhidos para significar na cultura não são quaisquer. Muito menos são arbitrários. Por que este e não aquele animal? Por que esta planta e não aquela? Um dos desafios maiores que as obras em questão enfrentaram foi 
demonstrar em cada caso que a resposta a esta pergunta é perfeitamente codificada e que este pensamento em estado selvagem é tão lógico, tão coerente e tão rigoroso quanto o é o pensamento domesticado.

Na parte de seus estudos dedicada à mitologia, LéviStrauss aplicou-se inicialmente à recuperação do mito como positividade comunicacional. Para isso empreendeu uma severa revisão das abordagens que em seu entendimento reduziam a narrativa mítica a algo diferente de si mesma. Começou censurando os que tomavam o mito como discurso cuja importância estaria em dizer coisas distintas daquelas que expressa efetivamente, repreendendo quem o encarava como linguagem incapaz de exprimir sua mensagem tão bem quanto outras e retificando quem o considerava como discurso tematizando apenas coisas absurdas ou nada exprimindo.

Na prática esta revisão significou distanciar-se daqueles que veem o mito como subproduto ou encenação de sentimentos humanos fundamentais - amor, ódio, inveja, ciúme, medo, vergonha, etc. Significou também afastar-se daqueles que se limitavam a reduzir os mitos a teorias explicativas sobre fenômenos naturais de difícil compreensão (lua, sol, estrelas, fogo, relâmpagos, trovões, eclipses...). Igualmente exigiu criticar aqueles que enxergavam a mitologia como um conjunto de discursos de segunda ordem, discursos que funcionam meramente como reflexos ou como sintomas de fenômenos de outro nível - eventos históricos, costumes ou contradições sociais, por exemplo - este sim o nível verdadeiramente importante.

Para Lévi-Strauss, como os sistemas de parentesco e as línguas, os mitos expressam o funcionamento do pensamento que os gerou. Mas o fazem de um modo comparativamente mais livre. E esta liberdade é fundamental para sua teoria da mitologia. Essencialmente liberados de quaisquer funções práticas, os mitos apresentam-se como uma espécie de atividade pura do espírito: neles o pensamento encontra-se menos submetido às pressões das circunstâncias externas e depende quase apenas de suas coerções internas. De um ponto de vista comunicacional esta positivação do mito significa encará-lo como forma específica de discurso que em si mesmo diz perfeitamente bem tudo o que tem a dizer, sem necessidade de redução a algo exterior.

Uma hipótese fundamental nessa perspectiva, inspirada no modelo linguístico mencionado no início deste trabalho - que considera que as relações têm prioridade com respeito aos elementos - é que os mitos formam sistemas, ao menos no plano de uma sociedade ou de um conjunto de sociedades vizinhas. É neste nível sistemático que devem ser abordados, pois os mitos não apenas são portadores de mensagens: também dialogam e se comunicam entre si, uma vez que cada mito revela seu significado em outro, que remete a um terceiro, que [...] Repete-se e inova ao mesmo tempo, crescendo como espiral.
Outra hipótese importante do ponto de vista comunicacional na abordagem dos mitos por Lévi-Strauss é a que os situa como narrativas de um tipo específico, dotado de uma lógica própria, com uma gramática muito particular. Para Lévi-Strauss as mitologias são dotadas de uma coerência interna bem precisa, que contrasta com a ilusão de liberdade total. Esta ilusão pode ser sugerida pela independência da linguagem dos mitos em relação à realidade exterior, pela capacidade que ela tem de transcender os quadros de qualquer cultura localizada e por sua autonomia com relação a qualquer verossimilhança ou referente. Trata-se apenas de uma miragem de liberdade sem limites, pois as mitologias, segundo o autor, são regidas por uma gramática de pleno direito: apresentam um nível em que internamente a necessidade se revela - um nível que universalmente responde pela geração das mensagens míticas. Esta gramática é o que permite que quando considerados no nível dos sistemas que formam seja possível compreender os processos de formação dos mitos aqui ou alhures. Sob o ângulo dessa gramática, mitos aparentemente muito diferentes quanto aos conteúdos podem apresentar a mesma estrutura e pertencer ao mesmo sistema. As características desses códigos são relativamente invariantes, sob o aspecto formal e dependem daquelas operações lógicas já mencionadas, como as permutações, as inversões, as simetrias, repetições, analogias, mediações...

Nos quatro volumes das Mitológicas, Lévi-Strauss viajou em busca desta gramática. Esta longa aventura resultou em uma das mais fascinantes investigações relativas ao funcionamento da mente humana. Lévi-Strauss estudou várias centenas de mitos americanos e um punhado de variações destes. Interpretou-os, examinando a relação que cada um apresentava com os demais. Ao longo de mais de duas mil páginas, relatando os mitos fez literatura. Avaliou as teorias preexistentes concernentes à mitologia. Discutiu hipóteses acerca da história da ocupação humana do continente americano. Especulou acerca da relação entre mitologias e rituais. Teorizou sobre a natureza da criação poética. Refletiu sobre as relações entre as linguagens do mito, da música e da fala. Inspirado na linguística propôs um método de interpretação dos mitos.

Mas na longa viagem descobriu os limites e a natureza paradoxais do próprio ato de interpretar, cujo destino termina sendo o de incessantemente se transformar em mais um significado do relato mítico interpretado. LéviStrauss descobriu que o significado de um mito é sempre outro mito, que os mitos por este caminho multiplicamse indefinidamente e que dos fragmentos de um muitos novos mitos borbotoam. Descobriu que em uma cadeia metonímica sem fim aquilo que os mitos significam é a própria significação. Destino irônico e paradoxal, sintetizado em sua declaração de que as Mitológicas constituem o mito da mitologia.

Lévi-Strauss tentou abrigar-se desse destino paradoxal da interpretação fazendo recurso à linguagem da 
música. Este expediente se deu não apenas como uma estratégia de exposição de que ele explicitamente lançou mão no primeiro volume (nomeando os capítulos e partes destes como abertura, sinfonia, cantata, ária, fuga, rondó, sonata, interlúdio, suíte, tema, variações, etc.) e no "Finale", último capítulo do último volume das Mitológicas. A analogia entre as linguagens do mito e da música em seu pensamento já era uma intuição antiga, presente em escritos seus desde a década de 1950. Mas no decorrer dos volumes das Mitológicas a intuição e a analogia se fortaleceram como instrumento de análise e vieram a rivalizar com ou mesmo a suplantar o modelo de inspiração linguística.

\section{Outra hipótese importante do ponto de vista comunicacional na abordagem dos mitos por Lévi- Strauss é a que os situa como narrativas de um tipo específico, dotado de uma lógica própria, com uma gramática muito particular.}

Igualmente formas de comunicação, mas diferentemente da língua, a música e o mito encontram em comum uma liberdade maior com relação ao significado. No caso da música, valem apenas os significantes sonoros; no dos relatos míticos, são os significados linguísticos que se deslocam para um plano de importância secundária Em ambos os casos a relação emissor-receptor da comunicação linguística se inverte, pois, como Lévi-Strauss observou, neles é o segundo termo que se descobre significado pelas mensagens do primeiro: a mensagem do mito, como a da música, efetua-se e realiza seus efeitos através do ouvinte e por este.

\section{Considerações finais}

Centenário, no momento em que escrevo Claude LéviStrauss vive em Paris. Foi professor do Collège de France, é membro da Academia Francesa e doutor honoris causa de várias das mais importantes universidades do mundo. Além de celebridade de grande destaque no cenário acadêmico, tornou-se bastante conhecido de um público amplo após o extremo sucesso obtido por Tristes Trópicos em 1955. Neste livro Lévi-Strauss descreve o ambiente artístico de sua juventude e o seu despertar para as questões estéticas. Revela como descobriu na antropolo- gia sua verdadeira paixão, após haver estudado filosofia e direito. Confessa que foi este apaixonamento que o trouxe ao Brasil, onde lecionou sociologia na então recém-fundada Universidade de São Paulo, de 1935 a 1939, e também o levou a expedições por longínquas sociedades indígenas que viviam na região central do País. Em cada página de Tristes Trópicos Lévi-Strauss fascina mesmo o leitor leigo. Quase como um romancista, combina autobiografia intelectual, confissões, relato de viagens, sabedoria existencial, preocupação ecológica. Medita sobre como as viagens que nos aproximam de novas paisagens acabam por nos afastar de nós mesmos. E especula filosoficamente sobre os destinos da humanidade, neste Planeta "que apareceu sem o homem e deverá desaparecer sem ele" wamecos

\section{REFERÊNCIAS}

LÉVI-STRAUSS, Claude. A Origem das Maneiras à Mesa. Mitológicas 3. Cosac \& Naify, 2006.

. As Estruturas Elementares do Parentesco. Petrópolis: Vozes, 1982.

Do Mel às Cinzas. Mitológicas 2. São Paulo: Cosac \& Naify, 2005.

L'Homme Nu. Mytholigiques 4. Paris: Plon, 1971.

O Cru e o Cozido. Mitológicas 1. São Paulo: Cosac \& Naify, 2006.

O Pensamento Selvagem. São Paulo: Companhia Editora Nacional, 1976.

O Totemismo Hoje. Petrópolis: Vozes, 1975.

. Social structure. In: KROEBER, Alfred (Ed.). Anthropology To-Day. University of Chicago Press, 1953.

Tristes Trópicos. São Paulo: Anhembi, 1957.

MAUSS, Marcel. Ensaio sobre a Dádiva. In: Sociologia e Antropologia. São Paulo: Edusp, 1974. 